\title{
Opportunistic childhood vaccinations in emergency-Are we really missing anyone?
}

\author{
Ingrid Berling, BM Emergency Medicine Trainee ${ }^{a}$, \\ Jody Stephenson, $\mathrm{BN}^{\mathrm{b}, *}$, \\ Patrick Cashman, RN, BHSc, MPH\&TM, GCertAppMgt(Health) ${ }^{b}$, \\ Conrad Loten, MBBS FACEM ${ }^{\mathrm{a}}$, \\ Michelle Butler, BSc, Grad Dip Med Stat ${ }^{b}$, \\ David Durrheim, MBChB, DrPH, DCH, FAFPHM ${ }^{\text {b }}$
}

\author{
a John Hunter Hospital, Australia \\ ${ }^{\mathrm{b}}$ Hunter New England Local Health District-NSW, Australia
}

Received 27 July 2011; received in revised form 12 December 2011; accepted 12 December 2011

\section{KEYWORDS}

Immunisation;

Children;

Opportunistic;

Emergency

\begin{abstract}
Summary
Objectives: Every health service presentation of a child should be considered an opportunity to ensure optimal immunisation. Measures to limit missed opportunities for vaccination in local emergency departments (ED) should reflect the scale of opportunity and parental support of immunisation service delivery strategies.

Methods: The vaccination status of every child aged less than seven years that presented to a tertiary hospital ED over a three month period was identified using the Australian Childhood Immunisation Register (ACIR). Contra-indications to vaccination were determined from medical records. A telephone survey or posted survey was conducted with parents of eligible children to confirm ACIR status and whether they would have consented to receiving vaccinations during their presentation. ED records were reviewed for vaccination history recording and ACIR records were reviewed, after interview, to confirm parental reports that initial ACIR status was incorrect.

Results: Nine per cent $(215 / 2399)$ of children were identified as incompletely vaccinated according to ACIR. Forty-seven children were excluded. Of the remaining 168 children, 95 parents (57\%) participated. Thirty-eight children had no contra-indications and their parents would have consented to vaccination during their ED presentation. The vaccination status of $82 \%(78 / 95)$ was recorded in ED records, but was incorrect in 35 cases. Forty parents indicated that the ACIR record was incorrect and this was confirmed in 36 cases (90\%).
\end{abstract}

\footnotetext{
* Corresponding author. Tel.: +61 2 49246477; fax: +61 249246490.
}

E-mail addresses: ingrid.berling@gmail.com (I. Berling), jody.stephenson@hnehealth.nsw.gov.au (J. Stephenson), Patrick.Cashman@hnehealth.nsw.gov.au (P. Cashman), Conrad.Loten@hnehealth.nsw.gov.au (C. Loten), michelle.butler@hnehealth.nsw.gov.au (M. Butler), david.durrheim@hnehealth.nsw.gov.au (D. Durrheim). 
Conclusions: There were missed opportunities to vaccinate a small proportion of children in ED. Parents provided a more accurate timely history of immunisation status than ACIR and thus ED staff should ensure that parents are always asked whether their child is fully vaccinated and provide or encourage vaccination.

Crown Copyright (c) 2012 Published by Elsevier Ltd on behalf of College of Emergency Nursing Australasia Ltd. All rights reserved.

What is known

- Emergency departments (ED) in Australia manage an increasing burden of lower acuity presentation in triage categories 4 and 5.

- Doctors and nurses have been shown to incorrectly documents a childs immunisation history, leaving the child vulnerable to vaccine prevenatable diseases.

\section{What this paper adds?}

- A small number of studies have suggested that hospital presentations are a large source of missed opportunities.

- In the Hunter region, we found there were only a small number of children, $1.6 \%(n=38 / 2399)$, who presented to the Emergency Department and had missed a true opportunity for immunisation.

\section{Introduction}

Emergency departments (ED) in Australia manage an increasing burden of lower acuity presentation in triage categories 4 and $5 .{ }^{1}$ Access to general practice, relative convenience, cost and ease of transport are all reasons cited for increasing primary health care use of EDs. ${ }^{2} \mathrm{~A}$ recent Australian study of primary care presentations in EDs noted that children $0-4$ years accounted for the largest agegroup (14\%) of primary health care presentations. ${ }^{2}$ Thus, there is an opportunity to offer primary prevention messages and measures to the parents of young children in EDs.

Childhood immunisation is a cost-effective public health strategy for reducing morbidity and mortality associated with many viral and bacterial diseases. ${ }^{3}$ Vaccination not only offers protection to the individual, but also offers protection to others within the community, in particular the elderly, the young and the unvaccinated. Every contact with a health service should be considered an opportunity to ensure that children are fully immunised. . $^{3,4}$

The Australian Childhood Immunisation Register (ACIR) is a national register administered by Medicare Australia that records details of vaccinations administered to children under seven years of age who live in Australia. It was established in 1996 in response to a decline in childhood immunisation levels and an increase in preventable childhood diseases. ${ }^{5}$ Immunisation coverage in the Greater Newcastle cluster, the population served by the John Hunter Hospital, has historically been relatively high with $93.5 \%$ at 12 months, $96.2 \%$ at 2 years and $91.2 \%$ at 5 years during 2009.
Missed opportunities for childhood immunisations are defined as children who attend a health care service, who were identified as incompletely immunised, had no contraindications to vaccination, yet did not receive the vaccinations for which they were due. A complete immunisation history is defined as 'being up to date' with the National Immunisation Program Schedule. As new vaccines are regularly added to the national immunisation schedule, this may make it hard for parents and medical staff to feel confident they can correctly remember immunisation status or rely on correct records (Fig. 1). ${ }^{3}$

In Australia, there is little research on opportunistic immunisation targeting children in EDs. A study at Sydney Children's Hospital found that $17 \%$ of children presenting to ED were not fully vaccinated, and immunisation status recording was as low as $76 \% .^{6}$

The identification of under-vaccinated children in EDs may not always be occurring. ${ }^{7}$

The aim of the present study was to determine the scale of missed opportunities for vaccination in children presenting to a large tertiary level hospital ED located in Newcastle NSW and to explore parental willingness to provide consent for their child to be vaccinated during ED presentations.

\section{Methods}

All children aged less than seven years (the age cut-off of ACIR records), who prospectively presented to John Hunter Hospital ED during a three month period (1st March 2010-31st May 2010) were matched with their ACIR records following their presentation (at the end of each month) to identify those who were incompletely vaccinated. Their medical record from the ED visit was audited for documentation of vaccination status and any contra-indications leading to exclusion of vaccination during attendance, including:

- Temperature above 38.5 degrees (at any point during presentation).

- Documented conscientious objector.

- Immuno-compromised/medical reason (e.g. seizure as presentation reason).

- Anaphylaxis following previous dose of relevant vaccine.

- Referral to a GP after hours clinic (GPAAH) from triage without ED consultation and patients that did not wait to be seen (DNW).

Guardians/parents of incompletely vaccinated children with no documented exclusion criterion were then contacted by letter to offer participation in a brief survey. A questionnaire and self-addressed reply-paid envelope were included. The questionnaire (see Appendix A) asked whether the parent was aware their child was overdue, if they would have consented to their child being vaccinated, if offered 


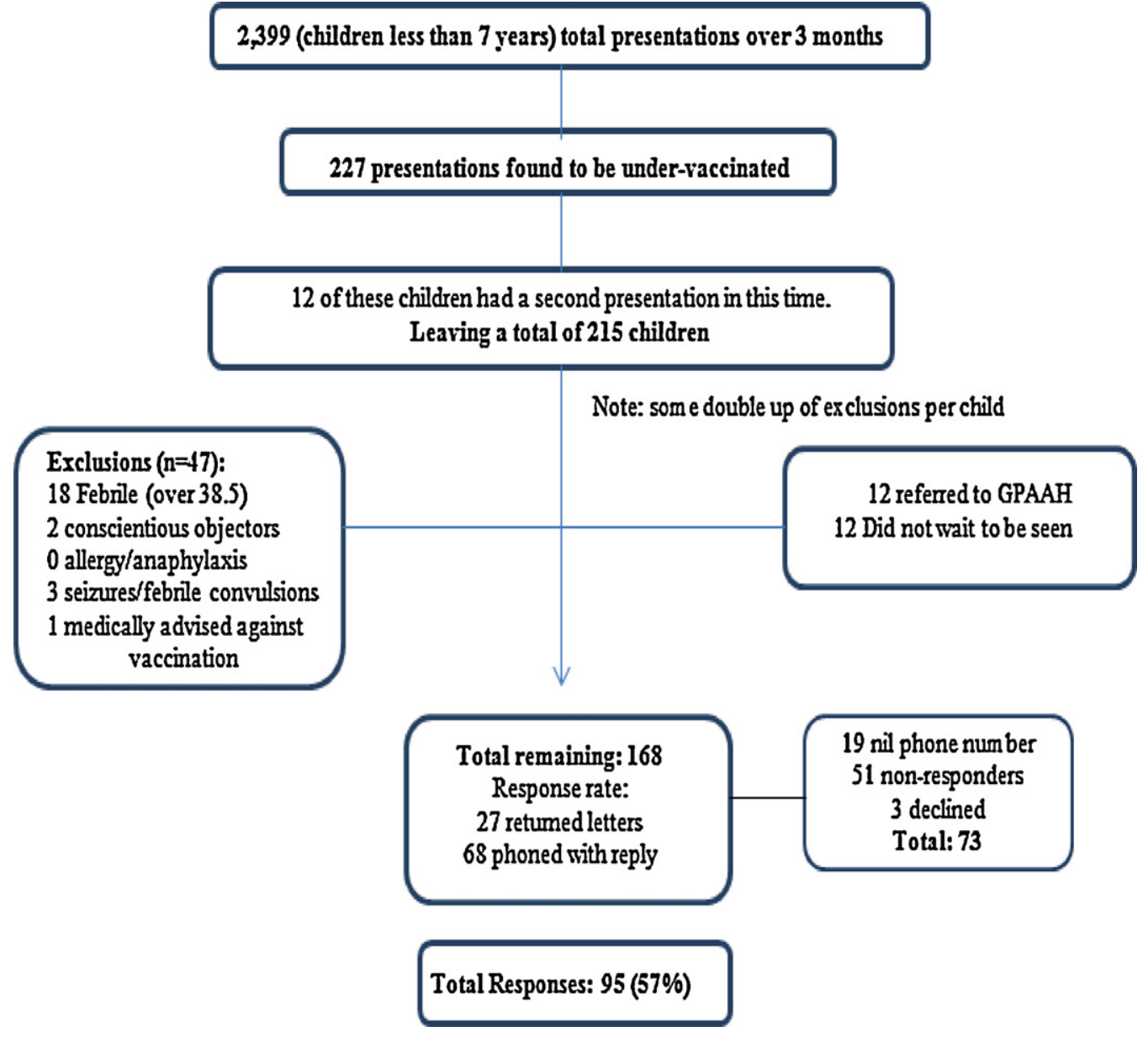

Figure 1 Study enrolment.

during their child's recent ED attendance and reasons why their child was overdue. A follow-up telephone call to any participants who had not replied was made, with a verbal consent process followed by telephone survey to collect the information.

ED notes were reviewed to confirm whether an accurate vaccination history was recorded by ED staff and ACIR records were reviewed after interview to confirm parental reports that initial recorded status was incorrect.

\section{Study setting}

Newcastle is a city of approximately 400,000 residents in northern NSW, Australia with a large transitory population, a working port with regular cruise ships, a large military base and a university with a high rate of international students. John Hunter Hospital is a tertiary level hospital located in Newcastle, NSW. The hospital services Newcastle, Lake Macquarie, the Hunter New England region and referrals from upper NSW. John Hunter Hospital ED is the busiest emergency department in NSW, and sees on average 68,000 presentations annually. Of this, approximately 9400 presentations are children aged less than seven. It is a combined adult and paediatric unit, with eight paediatric beds and two paediatric nurses per shift.
Results were recorded in a dedicated Microsoft Excel ${ }^{T M}$ 2010 spread sheet. Data was analysed using SAS version 9.2 (SAS Institute, Cary, NC 2008). Descriptive statistics were obtained through frequency distribution; $P$-values were generated from calculating a two sample test of proportions (alpha +0.05). This study was approved by the Hunter New England Human Research Ethics Committee, HNEHREC reference number: 10/01/21/5.04. Informed consent was obtained before participation in the questionnaire.

\section{Results}

Of the 2399 presentations over three months, $9 \%(n=215)$ of children were identified on ACIR as incompletely immunised. Of these identified children 26\% $(n=47)$ were excluded for the following reasons; conscientious objectors $(n=2)$, contra-indications such as fever or seizure $(n=22)$, not reviewed by ED staff $(n=24)$, this is defined as not waiting to be seen or referral onto General Practice from triage. One child had more than one exclusion reason leaving 168 children eligible for inclusion in the study (Table 1).

The demographic characteristics between the total study population and the children identified as under immunised on ACIR were matched for age, gender, urban/rural (using ARIA), socio-economic status (using SEIFA with cut off was 
Table 1 Demographics of the ACIR identified and all presenting children to John Hunter Hospital ED 1 March-31 May 2010.

\begin{tabular}{lllc}
\hline & Identified on ACIR $(n=215)$ & Overall presentations $(n=2399)$ & $P$ value \\
\hline Age (years) & Mean age 2.54 (SD 1.47) & Mean age 2.58 (SD 1.63) & 0.73 \\
Sex & 136 male $(63.26 \%)$ & 1398 male $(58.27 \%)$ & 0.15 \\
Urban/rural (access to services) & 211 urban $(98.14 \%)$ & 2360 urban $(98.37 \%)$ & 0.8 \\
Socio-economic status & 107 low $(49.77 \%)$ & 1086 low $(45.27 \%)$ & 0.2 \\
Aboriginal and Torres Strait Islander & 17 ATSI (7.91\%) & 132 ATSI (5.51\%) & 0.1 \\
Country of origin & 201 Australian $(93.49 \%)$ & 2352 Australian $(98.04 \%)$ & $<0.05$ \\
Insurance status (private/public) & 31 private $(14.42 \%)$ & $463(19.3 \%)$ & 0.08 \\
\hline
\end{tabular}

Table 2 Demographics of responders and non-responders.

\begin{tabular}{llll}
\hline & Responders $(n=95)$ & Non-responders $(n=73)$ & $P$ value \\
\hline Age & $2.67(1.52)$ & $2.59(1.48)$ & 0.73 \\
Sex & 60 male $(63.16 \%)$ & 48 male $(65.74 \%)$ & 0.73 \\
Access the services & 95 urban $(100 \%)$ & 69 urban $(94.52 \%)$ & 0.02 \\
Socio-economic status & 50 low $(52.63 \%)$ & 38 low $(52.05 \%)$ & 0.94 \\
Aboriginal and Torres Strait Islander & $4(4.21 \%)$ & $10(13.70 \%)$ & 0.03 \\
Country of origin & 7 overseas $(7.37 \%)$ & 5 overseas $(6.85 \%)$ & 0.9 \\
Insurance status & 15 private $(15.79 \%)$ & $10(13.7 \%)$ & 0.7 \\
\hline
\end{tabular}

determined by NSW average), country of origin and insurance status (Table 1)..$^{8,9}$ The only statistically different demographic was country of origin.

We achieved a response rate of $57 \%(n=96 / 158)$. The 73 who failed to respond were matched demographically against the responders to determine any difference (Table 2). The non-responder group was more likely to be of Aboriginal or Torres Strait Islander decent and live in rural areaswith less access to health services.

From the 95 responses, 40 stated that the ACIR data was in-correct, i.e. their child was up to date for immunisations and 8 were conscientious objectors not previously documented on ACIR (Table 3). On detailed review two months later, $70 \%(n=28 / 40)$ of the children whose parents had stated the ACIR data was incorrect, had an updated $A C I R$ record showing their parents had been correct. Of the remaining 48 children, who were eligible for vaccination and replied, 38 (79\%) had no contra-indications to vaccination recorded and would have consented to having their child vaccinated during their ED presentation. Therefore only 38 children (1.6\%, 38/2399) aged less than seven years who presented over the three month period were true opportunities for immunisation.

Of the 95 responders to our questionnaire immunisation status was recorded by either medical staff or nursing staff for $82 \%(n=78)$ children. Therefore $18 \%(n=17)$ did not have a record by nursing or medical staff of their vaccination status in their ED record (Table 4).

Of the 78 children with ED documentation of their vaccination status, $83 \%(n=65 / 78)$ of children were recorded by ED staff as up to date with their vaccinations. Of this group, 30 parents indicated that the ACIR data was incorrect, leaving 35 with an incorrectly recorded immunisation status. A total of $17 \%(n=13 / 78)$ of children were correctly identified as overdue. Therefore, $55 \%(n=43 / 78)$ of patients' records had correct documentation by emergency staff. The most commonly overdue vaccination was the 18 month varicella immunisation (Table 5).

During the three month period, there were three noted cases of children presenting with a vaccine preventable disease. One child was noted as being overdue for scheduled 2 month vaccinations during their presentation and was

Table 3 Reasons provided for why child was incompletely vaccinated.

\begin{tabular}{lll}
\hline & Number & $\begin{array}{l}\text { Would consent } \\
\text { to vaccination } \\
\text { in ED }\end{array}$ \\
\hline $\begin{array}{l}\text { Unaware my child } \\
\text { was overdue }\end{array}$ & 19 & 18 \\
$\begin{array}{l}\text { Incorrect ACIR data } \\
\begin{array}{l}\text { Felt child had been } \\
\text { too sick }\end{array}\end{array}$ & 40 & NA \\
$\begin{array}{l}\text { Born overseas and } \\
\text { requiring catch-ups }\end{array}$ & 5 & 5 \\
$\begin{array}{l}\text { Visiting from } \\
\text { overseas/interstate }\end{array}$ & 2 & 4 \\
$\begin{array}{l}\text { Difficultly accessing } \\
\text { GP }\end{array}$ & 8 & 7 \\
$\begin{array}{l}\text { Conscientious } \\
\text { objector }\end{array}$ & 8 & NA \\
$\begin{array}{l}\text { Other } \\
\text { Total }\end{array}$ & 5 & 2 \\
\hline
\end{tabular}


Table 4 Responders medical record vaccination status $(n=95)$.

\begin{tabular}{llll}
\hline & $\begin{array}{l}\text { Overdue Parent } \\
\text { as per } \\
\text { ACIR }\end{array}$ & $\begin{array}{l}\text { states ACIR } \\
\text { incorrect }\end{array}$ & $\begin{array}{l}\text { Number correctly } \\
\text { recorded as per } \\
\text { parent }\end{array}$ \\
\hline $\begin{array}{c}\text { Nil recorded } \\
\text { immunisation } \\
\text { history }\end{array}$ & 17 & 10 & Not applicable \\
$\begin{array}{c}\text { Recorded as } \\
\text { overdue } \\
\text { Recorded as } \\
\text { up to date }\end{array}$ & 13 & 0 & 13 \\
\hline
\end{tabular}

treated with antibiotics specifically as they were not vaccinated. Two children presented with cases of chickenpox and were over-due for their varicella vaccination.

\section{Discussion}

Immunisation prevents disease, and is one of the most effective measures in public health. The ongoing use of vaccinations has reduced the burden of many viral and bacterial diseases. ${ }^{3}$ Increased rates of vaccination help reduce the spread of infection by lifting the general level of immunity within a community.

We have shown that there are only a small number of children presenting to John Hunter Hospital Emergency Department that are missing a true opportunity for vaccination. The major barriers to immunisation in ACIR identified children were medical exclusions (fever or seizures) and parental disagreement with $A C I R$ recorded immunisation status. A number of the under-immunised children did not have their immunisation status recorded by ED doctors or nurses during their presentation. Additionally, children had an incorrect immunisation status recorded by ED staff. Identification of immunisation status is necessary to address possible opportunities for immunisation. Documentation by emergency staff is inadequate, and often incorrect.

Only $82 \%$ of children in our study had a documented vaccination history by medical staff, and this was correct only $55 \%$ of the time. Children identified as under-immunised on ACIR were more likely to be of foreign origin than the full cohort. This is possibly because of differing immunisation schedules between countries, and difficulty for parents to access GPs on arrival in Australia. This demographic

Table 5 Missing vaccination by age due.

\begin{tabular}{lll}
\hline Age due & As identified on ACIR & Responders \\
\hline 2 months & 29 & 13 \\
4 months & 31 & 12 \\
6 months & 49 & 22 \\
12 months & 55 & 31 \\
18 months & 109 & 46 \\
4 years & 53 & 23 \\
\hline
\end{tabular}

Note: Children can be overdue for more than one age schedule. features should serve as a prompt for ED staff to enquire as to immunisation status.

The ACIR data was unreliable with $38 \%(n=36 / 95)$ of children incorrectly flagged as under-vaccinated. Parents' responses about their child's immunisation status were found to be the most accurate method of assessing immunisation status. Our data has shown there is a delay before ACIR can correctly identify children as overdue. The ACIR data was unreliable with $38 \%(n=36 / 95)$ children incorrectly flagged as under-vaccinated. Parents' responses about their child's immunisation status were found to be the most accurate method of assessing immunisation status. A previous study in 1997 into the validity of the ACIR database suggested that more than half the children identified by ACIR as 'overdue' were fully immunised, and cited the reason as failure to return encounter forms. ${ }^{10}$

Another study found that incorrectly completed encounter forms and failure to record vaccinations administered overseas as the main reason for ACIR discrepancies, as well as failure to record overseas vaccinations. ${ }^{11}$ Since these studies, electronic return methods have been implemented in an attempt to reduce this problem. Two American studies examined the validity of immunisation histories given by parents. ${ }^{12,13}$ They found that although $91.5 \%$ of parents or guardians thought their child was up to date, only $66 \%$ were correct. They concluded this was not accurate enough to base clinical decisions on. In our study however, parents' responses about their child's immunisation status, in a population with high background immunisation coverage, were found to be a relatively accurate and reliable method of assessing immunisation status.

A small number of studies have suggested that hospital presentations are a large source of missed opportunities. ${ }^{14}$ However, in the Hunter region, we found that for a small number of children, $1.6 \%(n=38 / 2399)$ who presented to the Emergency Department and had missed a true opportunity for immunisation. The varicella vaccination (18 month) was the most commonly overdue vaccine, as was found in a previous small study in the Sydney children's hospital. This may be related to the fact that it is the second most recent addition to the vaccination schedule, and is due at an age when no other vaccinations are due.

\section{Limitations of the study}

The study is limited by its retrospective design and relatively short time period. Our population is specific to the Hunter New England region. It is unlikely that seasonal differences in missed opportunities exist but this could be explored by extending the period of study to a full year. It would have been preferable to have a higher response rate and so interpretation of results should be with caution. There was a large drop-out rate between the number of children identified as under-vaccinated and acceptance of our questionnaire and further details. This could also have created an enrolment bias. Unfortunately, the ACIR data was not as accurate as we had thought, and this initially suggested a larger number of children under-vaccinated. On retrospective review, ACIR data became more accurate with time, and had we waited longer between the month of sampling and the patient matching this could have been more accurate. 


\section{Recommendations for emergency medicine}

Emergency departments acknowledge that they have a role to play in the implementation of immunisation programs. ${ }^{4}$ Although opportunistically immunising children during their emergency presentation may not be sustainable for the number of presentations, conscious acknowledgement of the child being over-due and parental reminders will, and has, made a difference.

\section{Conclusions}

There are still missed opportunities for ED staff to determine the immunisation status of presenting children from their parents. This is particularly important for children not born in Australia. The possibility of offering immunisation or arranging catch-up immunisation during the presentation should be explored further. Medicare needs to promote timeliness of reporting data to ACIR by immunisation providers.

\section{Provenance and conflict of interest}

The authors have no conflicts of interest to declare. This paper was not commissioned.

\section{Human Research Ethics Approval}

This paper reports the findings of a research study that adhered to the National Statement on the Conduct of Human Research by the Australian National Health and Medical Research Council, and has been approved by the Hunter New England Human Research Ethics Committee Approval Reference number 10/01/21/5.04.

\section{Acknowledgements}

Dr Andy Way for his assistance with creating a spread sheet for the iPIMS data. 


\section{Appendix A. Questionnaire}

Division of Emergency Medicine

John Heater Hoopital

Locked Bag No i

Heater Regioe Maid Ceatre NSw 2310

\section{HUNTER NEW ENGLAND NSWOHEALTH}

\section{QUESTIONNAIRE}

Please take your time to answer the following questions, or decline participation (tick) $\square$ :

1. Were you aware your child is recordad as overdue for their [insert] vaccination? Yes/No

2. During your recent emergency department presentation, if routine Vaccinations had been offered, would you have agread to your child receiving a vaccination?

3. From the below options, which scenario best describes the reason your child was overdue vaccinations?

[ Unaware child was owerdue

(1) Your child is vaccinated, and we have incorrect data

口 You were concemed your child was too sick:

口 Your child was bom oversasa and requiring catch up vaccinations

口 You are visiting from interstate/oversex
口 You have difificulty accessing immunization service providers, such as your GP

1] You have conscientious objections to immunization

$\square$ Other

4. If vaccinations were available within the hospital at a free clinic for you and your family would you accass such a clinic?

Yes/No

If you would not like not to be mailed copy of the final report from this resarch, please tick: $\square$ Do not mail me a copy

Thank you, your response is kindly appreciated.

Pleses retum this questionnaire in the self-adiressed reply-paid envelope.

Dr Ingrid Berling

Emergency Registrar

24 March $2010 \mathrm{v} 4$ 


\section{References}

1. Dunn R, Dillay S, Brookes J, Leach D, Maclean A, Rogers I, et al., editors. The emergency medicine manual. 4th ed. Tennyson, SA 5022: Venom Publishing; 2006.

2. Siminski P, Bezzina AJ, Lago LP, Eagar K. Primary care presentations at emergency departments: rates and reasons by age and sex. Australian Health Review 2008;32(4):700-9.

3. N.H.M.R.C., editor. Australian Immunisation Handbook. Ninth ed. Australian Government Department of Health and Aging; 2008.

4. Australasian College for Emergency Medicine Policy of Immunisation in Emergency Department July 2005. Available URL: www.acem.org.au/media/policies_and_guidelines/ immunisation.pdf [accessed 10.12.11].

5. Australian Childhood Immunisation Register. 2009 [cited 2009 24 April]; Available from: http: / / www.medicare.gov.au/public/ services/acir/about.jsp.

6. Udovic SL, Lieu TA, Black SB, Ray PM, Ray GT, Shinefield HR. Parent reports on willingness to accept childhood immunizations during urgent care visits. Pediatrics 1998;102(4):E47.

7. Iskander M, Booy R, Lambert S. The burden of influenza in children. Current Opinion in Infectious Diseases 2007;20(3):259-63.

8. Information Paper: Census of Population and Housing- SocioEconomic Indexes for Areas, Australia (SEIFA 2001). 2003 Commonwealth of Australia. Available from: http://www.abs. gov.au.
9. Measuring Remoteness: Accessibility/Remoteness Index of Australia (ARIA) Revised Edition. 2001 Department of Health and Aged Care. Available from: http://ww.health.gov.au/publicat. htm.

10. Conaty S, McAnulty J. The Australian Childhood Immunisation Register: validation of the immunisation status of children who are very overdue. Australian \& New Zealand Journal of Public Health 2001;25(2):138-40.

11. Botham S, Poulos RG, McFarland KJ, Ferson MJ. Getting it right-the Australian Childhood Immunisation Register and immunisation rates in south-eastern Sydney. Australian \& New Zealand Journal of Public Health 2004;28(1): 68-71.

12. Williams ER, Meza YE, Salazar S, Dominici P, Fasano CJ. Immunization histories given by adult caregivers accompanying children 3-36 months to the emergency department: are their histories valid for the haemophilus influenzae $B$ and pneumococcal vaccines? Pediatric Emergency Care 2007;23(5): 285-8.

13. Goldstein KP, Kviz FJ, Daum RS. Accuracy of immunization histories provided by adults accompanying preschool children to a pediatric emergency department. Journal of the American Medical Association 1993;270(18):2190-4.

14. Ressler KA, Orr K, Bowder S, Grove S, Best P, Ferson MJ. Opportunistic immunisation of infants admitted to hospital: are we doing enough? Journal of Paediatrics and Child Health 2008;44(6):317-20. 